\title{
DEL PASADO AL PRESENTE. SOBRE EL CAMBIO DEL CONCEPTO DE IMITACIÓN EN EL SIGLO XVIII ESPAÑOL
}

\author{
De una parte, el arte imita a la naturaleza; \\ de otra, lleva a cabo lo que ella \\ es incapaz de realizar.
}

ARISTÓteles, Física

Imitar e inventar son en nuestra sociedad de hoy antónimos. Sin embargo, hubo un tiempo en que "fueron la misma cosa", como dijo Lope en La Dorotea. Para nosotros, el arte ahora está prácticamente desprovisto de implicaciones morales y los juicios que se aplican a las obras que someten a nuestra consideración rara vez aluden a esta condición de la obra artística. Mucho se ha debatido sobre la ética de la estética y viceversa, y ya casi nadie admite descalificaciones o valoraciones artísticas basadas en criterios éticos.

Sin embargo, no siempre fue así. Precisamente fue lo ético, lo moral, lo que hizo muchas veces que se permitiera existir al arte. Así sucede con Platón, que nos habla de mimesis en los libros III y X de la República. En el III distingue a la comedia y a la tragedia como las formas de representación directa (mimesis). El problema para Platón era saber si estas artes tenían lugar dentro de la República y si los guardianes del Estado debían o no ser hábiles en la imitación (394 e). Rápidamente Platón pasa del plano estético al ético. Estos guardianes del Estado sólo deben imitar cualidades irreprochables del hombre libre: valor, generosidad, templanza, y explícitamente señala que no deben imitar ni vicios ni bajezas, si no es para educar. El arte encuentra la justificación de su existencia por vía moral. En la medida en que la imitación supone para Platón cierta identificación, el hombre virtuoso no podrá imitar más que a hombres virtuosos. Todo lo que tiene que ver con el amor, la locura, la enfermedad, se niega. 
Dado que se busca lo moral y la educación, se desdeñarán también, en el libro X, las ficciones que tienen por objeto la ilusión, no la verdad ni la virtud. Se rechaza todo arte que no sea utilitario. Además, la imitación se entiende como algo nocivo porque tiene "comercio, unión y amistad con la parte de nosotros mismos que repugna a la sabiduría" (603 b). Excita las pasiones y engendra problemas (604 d-605 a). Platón niega valor a la poesía y a la pintura. Niega el arte y la mimesis porque no son verdaderos ni virtuosos.

Aristóteles, sin embargo, es partidario precisamente de las artes de imitación que Platón rechazó. Se basa sobre todo en la danza y en la música; es decir, en el ritmo. Le parece que la imitación es innata a la persona y que imitar y ver imitaciones es una fuente de placer para el hombre porque encuentra semejanzas con la vida real. Ésta es la primera vez que el concepto de imitación se relaciona con seres reales, como ha señalado Mortier ${ }^{1}$. Por esto, privilegia la imitación directa, la que se hace con personajes en acción (y no sólo por medio de la palabra o el verso), y en la que no se narran cosas, sino que se presentan. Alejándose de la morafidad platoniana, se fija en la importancia de la verosimilitud y en el carácter artificial del objeto literario. Para él, la imitación tiene por objeto al hombre, sus costumbres, carácter, pasiones, etc. Esta forma de entender la imitación es esencialmente dialéctica, pues interesan las costumbres y caracteres del hombre en cada momento histórico.

Horacio hará explícito el "enseñar deleitando" que se apuntaba en Platón como justificación del arte, del mismo modo que planteará o replanteará problemas como la relación "ingenio/arte", "decoro", etcétera.

Estas cuestiones: "ingenio/arte", "decoro", la polémica sobre si el poeta nacía o se hacía, la pregunta acerca de lo que existiera antes: la poesía o las reglas, así como otras que vinculaban la imitación al estado religioso de los hombres, de forma que la imagen de Cristo se convertía en el modelo máximo imitable ${ }^{2}$,

${ }^{1}$ R. Mortier, L'originalité, Droz, Genève, 1982, p. 17. Un planteamiento general en R. Wellek y A. Warren, Teoria literaria, Gredos, Madrid, 1953.

2 Véase A. García Berrio, Formación de la teoría literaria moderna, t. 1 , CUPSA, Madrid, 1977 y t. 2, Universidad, Murcia, 1980. Los teóricos adoctrinaron según las poéticas, no según la escritura contemporánea, y para avalar su inmovilismo se basaron en dos hechos. Primero, en que Aristóteles había dicho que las "fábulas heredadas" no debían alterarse - y esto se entendió como fidelidad a los modelos, no como conservación de una herencia literaria 
se fueron desarrollando desde la Edad Media hasta el siglo XviII. El platonismo del ideal de la naturaleza convivió con la tendencia renacentista a liberarse de las trabas estéticas medievales. Se llegó a un manierismo en las formas, que era la expresión más elaborada del idealismo. La imitación y la originalidad se mantuvieron dentro de los márgenes que las poéticas propugnaban, oscilando entre conceder más importancia al ingenio, o dársela al arte.

Los preceptistas del siglo XVIII ejemplifican también estas posturas, pero durante ese siglo se producen cambios fundamentales, y uno de ellos tiene que ver con el concepto de imitación.

Vamos a ver ahora cómo se desarrolla este concepto y qué factores intervienen para que se produzca el cambio. Veremos primero cuál era la situación y después los factores que intervienen en el cambio, centrándonos $a$ ) en la filosofía sensista; $b$ ) en la presión de la corriente tradicionalista; $c$ ) en la incidencia de los que propugnaban la originalidad, y $d$ ) en el elemento extraliterario económico y social. Incorporar lo económico y social tiene importancia en esta época de grandes transformaciones.

En primer lugar, la preceptiva tradicional suponía que a la tragedia y a la épica les correspondían personajes de noble cuna, a los que se suponía dotados de cualidades positivas y virtuosas; y a la comedia y a los géneros burlescos les correspondían personajes bajos y villanos. El lenguaje, gesto, acción, indumentaria, iban en relación con esta separación social. Por esto se daba, según mostró Castelvetro en sus Comentarios a la "Poética" de Aristóteles (1570), una unidad de clase, de lenguaje y, por esto, en el teatro, la escenografía que denotaba los "lugares de la acción" iba acorde con el tipo de personajes que aparecían. Si era tragedia, fachada noble, sillones e interiores serios; si comedia, calle popular, etc. Es decir, se trasladó al arte la jerarquía social de la realidad y se dio a los personajes los valores que la relación social había concedido a cada clase: el noble era justo, valiente, poderoso, porque ésos eran los valores que su clase encarnaba sustancialmente en la realidad, y el villano era eso, villano, ruin, etcétera.

Con la presión cada vez más fuerte de lo económico, con la aparición de una clase de personas que ejercía el control sobre los medios de producción y difusión, los valores se fueron trastrocando y la literatura presentó esos nuevos valores vigentes. Se va a

sujeta a la pervivencia y variación oral-y, segundo, en que Horacio había dejado escrita una casuística de la innovación, a la que había que ajustarse. 
dar a lo largo del xviII el cambio de un sistema que entiende la vida de una forma estática por otro que la concibe en movimiento. Los cambios sociales producirán cambios estéticos y las diferentes posturas ante el uso literario de esos cambios, es decir, ante el problema de la imitación y la innovación, se volcarán en la más amplia querella entre los antiguos y los modernos. Comenzará a crearse la llamada "conciencia moderna"3.

¿Qué se entendía por imitación a principios del siglo xviII? Siguiendo la corriente clásica, imitación era el resultado de copiar un modelo literario antiguo, avalado por la tradición. En definitiva, era ajustarse a las convenciones y características de un género dado. De esta forma hay que entender opiniones como las de Meléndez Valdés o Iglesias de las Casas, que se refieren a la imitación como a "plegarse al género" en que se proponen escribir. En este sentido debemos entender las palabras de Ben Jonson cuando decía que el tercer requisito del poeta era "saber imitar"'4.

Luzán, en el libro I, cap. 6 de su Poética, entiende que la imitación puede ser de lo universal y de lo particular, que hay que imitar a la Naturaleza, pero la Naturaleza no es algo abierto, cambiante, rico y variado, como dirá Erauso en 1750. La Naturaleza es un modelo, un como debe ser. El poeta tiene que consultar los mejores ejemplos que conozca con el fin de ofrecer la imagen más perfecta de lo que imita, no lo que ve. Esta visión implica una peculiar forma de lo que sea el realismo, que se radicalizará, como en el caso de Forner, para quien la imitación es sólo de lo universal, en el Cotejo de las églogas ${ }^{5}$.

${ }^{3}$ Véase J. A. Maravall, Antiguos y modernos, Alianza, Madrid, 1986.

${ }^{4}$ Cf. T. S. Eliot, "La época de Dryden", en Función de la poesía y función de la crítica, Seix-Barral, Barcelona, 1968, pp. 67-79, donde hace numerosas alusiones en este sentido.

${ }^{5}$ Véase J. P. Forner, Cotejo de las églogas que ha premiado la Academia..., ed. F. Lázaro, CSIC, Salamanca, 1960. MoraTín escribió en estos términos sobre invención e imitación: "Lo que se llama inventar en las artes no es otra cosa que imitar lo que existe en la naturaleza, o en las obras de los hombres, que la imitaron ya. El que se proponga no coincidir nunca en lo mismo que otros hicieron, se propone un método equivocado y absurdo, y el que huye de acomodar en sus obras las perfecciones de otro artífice, pudiendo hacerlo con oportunidad, voluntariamente yerra [...]. El que no estudia por buenos principios la razón de las artes, nada de esto entiende; y luego que halla en cualquier obra algún pasaje que tenga semejanza con otro, eso le basta para llamar plagio, copia, robo execrable, lo que es tal vez prueba de talento, con profunda meditación", Teatro completo, ed. F. Lázaro Carreter, Labor, Barce- 
Tal concepto de imitación -imitación de obras de arte- suponía la asimilación de la experiencia de los maestros y, al mismo tiempo, si se hacía bien, ponía de manifiesto la maestría propia, pues el autor sabía incorporarse a esa tradición. Así pues, lo que el poeta debía hacer era emular, o intentar emular, a sus predecesores. El Diccionario de Autoridades no recoge esta acepción de emular como "deseo de superación", pero el Dictionary of the English Language 6 de Samuel Johnson, sí. Emulación es "rivalidad, deseo de superioridad". Sin embargo, esté claro que, sin intentar emular, la imitación per se limitaba la experiencia artística y la materia literaria imitable. En cierto modo, lo que debía ser simplemente una imitación de modelos para aprender una técnica, parecía convertirse en lo fundamental y adquirir una importancia institucional que no tenía.

Quintiliano, en De Institutione Oratoria, libro X, cap. 2, había observado que la imitatio era el resultado activo de la lectura reiterada. Para él debía ir presidida por el propósito de superar al modelo: "imitatio per se ipsa non sufficit"' na, más o menos latente en todas las declaraciones poéticas, pierde intensidad a lo largo de la historia, aunque encontremos ejemplos de ella.

Lo normal son opiniones como la de Luis José Velázquez en los Origenes de la poesía castellana quien, al referirse al inmejorable estado de la poesía en el siglo XVI, lo achaca a que "se leían, se imitaban y se traducían los mejores originales de los griegos y latinos; y los grandes maestros del Arte, Aristóteles y Horacio, lo eran así mismo de toda la Nación" ". La misma opinión mantenía en 1798 José de Goya y Muniáin en su traducción de la Poética de Aristóteles. Esta concepción de la imitación permaneció hasta fines del siglo. En realidad, penetró gran parte de la siguiente centuria, aunque cada vez más encastillada en las academias.

lona, 1970 , t. 1, p. 232. Otra opinión tenía NASARRE, quien en el prólogo a su edición de las comedias de Cervantes, en 1749, dice: "La manera de pintar las cosas al natural, como lo hacían los antiguos, pareció muy simple y grosera a los modernos, que no queriendo dar cosa alguna a la naturaleza, y dándolo todo a su invención, transportaron sus oyentes a un mundo imaginario y fantástico, del cual nada se puede sacar de uso para la vida humana" (s.p.).

${ }^{6}$ T. 1 , London, 1755 , s. $v$.

${ }^{7}$ Véase H. Lausberg, Manual de retórica, Gredos, Madrid, 1975, t. 2, pp. 341 ss.

${ }^{8}$ L. J. VelázQuez, Origenes de la poesia castellana, Málaga, 1754, p. 67. Se refiere a lo que él llama tercera edad de la poesía castellana. 
Sin embargo, aunque se encuentren ejemplos antes, en 1706 , para no salirnos del arco temporal previsto, tenemos declaraciones en sentido contrario. El abate Masieu observaba: "El modo con que varían los hombres en sus juicios es una de las pruebas eficaces de la incertidumbre que se halla en las ideas que forman de las cosas"'. Palabras semejantes tendrá Feijoo sobre el gusto y el "no sé qué". Ese gusto "novelero" y ese "no sé qué" que Montesquieu, en su Essai sur le goût de 1757, hará depender de la sorpresa y en cierto modo de la originalidad.

Pero un ejemplo mejor encontramos en las Reflexiones sobre la poesía de N. Philoaletheias, cuando dice explícitamente:

Hemos visto que el fin del poeta es deleitar: luego, como no siempre los hombres se deleitan con los mismos objetos, la Poesía debe necesariamente variar [...]. Nada hay más inútil o acaso más pernicioso para formar el gusto que la lectura de los poetas antiguos, y de la Poética de Aristóteles.

Y, yendo más lejos, se pregunta:

¿Cómo se ha de saber, se dirá, la Poesía si no se estudian las reglas de ella? [Responde] Estudiando el corazón del hombre, el espíritu del siglo en que se vive $[\ldots]$, en una palabra, pensando ${ }^{10}$.

Philoaletheias nos dice con claridad que la literatura de cada época ha de ser según el gusto del momento en que se vive. Años después, en 1793, Santos Díez González se hará eco de esta forma cada vez más ascendente de entender la literatura y dirá, al definir la poesía dramática, que "propone ejemplos de la vida civil y privada" 11 . Es decir que, de forma cada vez más general, se va imponiendo esta consideración de la literatura como expresión del entorno.

Donde más se va a notar es en el teatro y en la novela. Mientras la poesía, salvo excepciones, tiene mínima repercusión en el público y se difunde entre los mismos poetas - contribuyendo es-

${ }^{9}$ Cit. por S. Dífz González, Instituciones poéticas, Cano, Madrid, 1793, p. ix. El "Discurso preliminar" es de este abate, extraído de la Colección de Memorias de la Academia Real de Inscripciones y Buenas Letras de París, 1717, t. 2, pp. 171 ss.

${ }^{10}$ N. Philoaletheias, Reflexiones sobre la poesia, Madrid, 1787. Ed. por J. L. Cano en Heierodoxos y prerrománticos, Júcar, Madrid, 1974. Las citas en las pp. 259 y 270.

11 Díez González, op. cit., p. 67. 
to al conservadurismo de las formas y modelos, aunque surjan géneros nuevos como la "poesía descriptiva" y aunque las sátiras sean siempre actuales - el teatro y la novela, que dependen absolutamente del favor del público, serán los que den cabida a estos cambios. Así Torres Villarroel, en Los desahuciados del mundo $y$ de la gloria (1736), en vez de referirse al cristalino río Zurguén - como hacían los poetas de la escuela salmantina-, nos hablará de "'los pajizos céspedes del sucio Zurguén, negro borrón' del Tormes ${ }^{12}$. Y Francisco de Tójar pondrá de manifiesto el cambio de actitud ya obrado, en La filósofa por amor, con estas palabras: "los autores estudiaron y buscaron el gusto de la nación, y colocaron sobre la escena a la nación misma'. Para añadir después: "el deber de un escritor [...] es pintar las costumbres"13. En 1797, Rodríguez de Arellano, al traducir Estela, de Florián, observa que los personajes, los pastores, son verosímiles porque su estilo es "natural, sencillo, proporcionado a su capacidad, situación y sentimientos' I4. La opinión de Arellano coincide aquí con la de Fielding, cuando dice en Tom Jones (1759) que lo verosímil se consigue si las acciones del personaje están acomodadas a las cualidades que lo conforman. Es lo que él llamaba "relación de caracteres". Estas declaraciones son puestas al día de lo que Aristóteles dejó escrito sobre este asunto ${ }^{15}$.

Los personajes, entonces, serán cotidianos y pequeños, sin la calidad de héroes de las novelas de caballerías, ni de galanes del Siglo de Oro, sin la idealización de las obras pastoriles. Serán mediocres como el entorno del lector. Y este cambio traerá otros muy significativos. Por ejemplo, la descripción de interiores e indumentarias. Este acercamiento a "los ejemplos de la vida civil y privada', como dijo Díez González, se veía completado con la ilustración de los textos mediante grabados ${ }^{16}$.

${ }^{12}$ Recordemos, por ejemplo, la letrilla de MELÉndez Valdés, "La flor del Zurguén", Poesías, ed. E. Palacios, Alhambra, Madrid, 1979, pp. 219 ss. DiEGO DE TORRES Villar ROEL, Los desahuciados dei mundo y de la gloria, ed. M. Ma Pérez, Editora Nacional, Madrid, 1979, p. 64.

${ }^{13}$ F. DE TÓJAR, La filósofa por amor, Barcelona, 1799, pp. 5 y 9.

${ }_{14}$ Florián, Estela, trad. Rodríguez de Arellano, Madrid, 1792, pp, i-ii.

15 Cumberland, Henry, 1795, lib. I, cap. 1, decía lo mismo. Cf. J. Álva. REZ BARRIENTos, "Algunas ideas sobre teoría de la novela en Inglaterra y España en el siglo XVIII", $A L E, 2$ (1983), 5-25.

16 Recordemos ahora Las tardes de la granja, o la traducción libre de Zavala y Zamora de las Novelas nuevas de FLORIÁN (1799), que tienen todas grabados, o la edición de 1809 de las Fábulas de este mismo autor, también traducidas por Zavala, que están "adornadas con 52 estampas finas". 
Tal forma de presentar la realidad tiene que ver con la manera de entender el realismo y la verosimilitud. Si Aristóteles había dado una definición de verosimilitud suficientemente amplia como para que cupiera todo en las obras de arte - pues Aristóteles pensaba que la imitación debía ser del hombre y cuanto le rodea-, en esta época bastantes autores la entienden, más que como "verdad poética', como verdad a secas. Así, los novelistas acumularán notas a pie de página para explicar las localizaciones espaciales, los hechos históricos, para aclarar la existencia real de este o aquel personaje, acumularán detalles, descripciones minuciosas (dando pie a la "minuciosidad holandesa"), etc. Todo esto acabará llevando al realismo y al costumbrismo ${ }^{17}$. Todo, ya lo dije, para dar una idea de credibilidad. Tójar, aunque no sea cierto, dirá: "el romance que yo presento, no es un romance: es una historia, y una historia verdadera'"18. Tengamos presente, además, el gancho que para muchos lectores tiene leer un suceso "real". El Padre Isla, en esta línea, manifestó que "el Antón Zotes que se tuvo presente [en Fray Gerundio] fue el mismísimo compadre de madre y vecino de la Antigua' 19 . Y en este sentido van las enumeraciones de las cualidades necesarias para escribir novelas: según Valladares de Sotomayor son "entendimiento, uso del mundo y conocimiento de las pasiones" 20 .

Así llegamos a la definición de verosimilitud de Díez González, después de entenderla como una convención, el ajuste a unos modelos y unas reglas. Verosímil será la obra que, "atendidas las circunstancias de la persona, lugar y tiempo, fuere creíble; o si no excediere el orden natural y posible de los acontecimientos",21

${ }^{17}$ Y también a la aparición del "color local". Dumas padre cuenta cómo hablando con un dramaturgo ya mayor, de tendencia neoclásica, le dijo que estaba escribiendo una obra de teatro "moderna", con color local, a lo que el viejo dramaturgo contestó: "en mi época eso no existía". Prosper Mérimée tiene también algunas páginas interesantes sobre la aparición del color local. Don Juan Valera, "Del Romanticismo en España, y de Espronceda", Estudios críticos..., Álvarez, Madrid, 1884, t. 1, p. 169, señaló: "Verdad es que este color local suele ser falso, y en tratándose de la Edad Media lúgubre en demasía'. Actualmente preparo un trabajo sobre este asunto.

${ }^{18}$ F. DE TÓJAR, op. cit., p. 10.

${ }^{19}$ Véase $B A E$, t. 15, p. 471. La carta es de 1758. Cit. por R. P. Sebold, introducción a Fray Gerundio de Campazas, Espasa-Calpe, Madrid, 1960, p. 148. Véase también las Cartas inéditas del Padre Isla, ed. L. Fernández, Madrid, 1957, p. 183, donde dice que "el gusto del público es el que nos ha de dar la ley".

${ }^{20}$ A. Valladares de Sotomayor, La Leandra, Ulloa, Madrid, 1797, p. 8.

${ }^{21}$ Díez González, op. cit., p. 69. 
Con esta relativización se creaba un nuevo tipo de personaje, reflejo del tipo real y acorde con la nueva forma de estudiar la historia. En palabra de Meléndez Valdés (carta a Jovellanos, 1778): " anotando su origen, sus progresos, variaciones y alteraciones, y las causas que las produjeron" 22 . Como señalaría Larra años después, no interesa "el hombre en general como anteriormente [...] lo habían dejado descrito, y como ya era de todos conocido, sino [el] hombre en combinación, en juego con las nuevas y especiales formas de la sociedad en que lo observan" 23 . Interesa representar, imitar al hombre en sociedad, porque ésta está naciendo, hasta el punto de llegar a preguntarse, con Toribio Núñez:

La sociedad: he aquí un nuevo personaje desconocido que viene a hacer papel en esta composición. ¿Y quién es este personaje? ¿De qué manera obra? ¿Cómo ejerce sus derechos? ¿Dónde reside? ¿Por qué señas se le puede conocer?24

Observemos que, justamente en los momentos de supuesto mayor desarrollo del individualismo, se habla del nacimiento de la sociedad, del hombre en combinación. La igualdad y la fraternidad del lema revolucionario francés, en cierto modo, hacían imposible la singularidad del hombre. Es ahora cuando los criterios vitales y morales de la burguesía comienzan a ejercer su influencia.

La sociedad se producía, según Thomas Paine, "por nuestras necesidades", porque fomentaba "de manera positiva nuestra felicidad uniendo nuestros afectos en cualquier Estado"25. Antes de Paine, en 1768, Romà y Rossell ya había puesto de relieve la importancia de la sociedad y la tendencia del hombre a vivir en ella. La industria llevaba a "la sociedad más dulce y agradable", y ésta era una de Las señales de la felicidad en España ${ }^{26}$. Será una

${ }^{22}$ Cf. Poetas líricos del siglo XviII, ed. L. A. Cueto, BAE, t. 61, p. 80.

${ }^{23}$ M. J. De Larra, Obras..., ed. C. Seco Serrano, BAE, t. 128, pp. 238b-239a.

${ }^{24}$ T. Túnéter, Ciencia social según los principios de Bentham, Madrid, 1835, p. 551. Cf. el artículo de J. A. Maravall, "Espíritu burgués y principio de interés personal en la Ilustración española", $H R, 47$ (1979), 291-325.

${ }^{25}$ En Common sense, 1776. Véase el interesante trabajo de H. AREndT, La condición humana, Barral, Barcelona, 1974, pp. 150 ss.

${ }^{26} \mathrm{~F}$. Romì Y Rossell, Las señales de la felicidad en España y medios para hacerlos eficaces, Madrid, 1768, p. 28. Felicidad tal y como la entendía JovellaNOs en el Discurso sobre los medios de promover la felicidad del Principado, no "en un sentido moral", sino como un "estado de abundancia y comodidades que debe procurar todo buen gobernante a sus individuos". Era la idea de felici- 
sociedad que glorifique el trabajo y, en consecuencia, que defienda la propiedad privada y a la familia, como guardiana de esa propiedad. De forma que se convertirá en una sociedad de trabajo y trabajadores (con la peculiaridad de que, ahora, esa sociedad no tiene trabajo para sus trabajadores) ${ }^{27}$.

Esta sociedad es la que aparece en los sainetes de Ramón de la Cruz. Ramón de la Cruz, en el prólogo que puso a la edición de su obra en 1786, hacía una defensa de su teatro, mostrando al tiempo el cambio que se había dado ya en la forma de entender la imitación. Los sainetes son
pintura exacta de la vida civil y de las costumbres españolas [...]. No hay ni hubo más invención en la dramática que copiar lo que se ve, esto es, retratar los hombres, sus palabras, sus acciones y sus costumbres [... ]. Los que han paseado el día de San Isidro su pra- dera, los que han visitado el Rastro por la mañana, la Plaza Mayor de Madrid la víspera de Navidad, el Prado antiguo por la noche [...] en una palabra, cuantos han visto mis sainetes, reducidos al corto espacio de veinticinco minutos de representación [...] digan si son copias o no de lo que ven sus ojos y de lo que oyen sus oídos; si los planes están arreglados al terreno que pisan, y si los cuadros no representan la historia de nuestro siglo ${ }^{28}$.

Ramón de la Cruz nos dice en pocas palabras cuál es su materia literaria: la realidad; cuáles los personajes de sus sainetes: los hombres de su siglo; qué pretende: imitar lo que ve; qué reproduce: la vida civil y las costumbres españolas, las palabras y las acciones de los hombres tal y como los oye y ve en su entorno. Su intención es representar la historia de su siglo ${ }^{29}$. Vemos, pues, que

dad expresada por L. MURATORI en La pública felicidad objeto de los buenos príncipes (1749), traducida en Madrid en 1790. Y este mismo debía ser el objetivo de los gobernantes, según Forner.

27 Por ejemplo, en La señorita malcriada de IRIARTE encontramos elogio de los comerciantes; VALENTÍN DE FORONDA escribirá en 1787 "Sobre lo honrosa que es la profesión del comercio", y como él otros escribirán haciéndose eco de la despenalización del trabajo. Recordemos también comedias como Los menestrales de TRigueros o La industriosa madrileña y el fabricante de Olot, o los efectos de la aplicación, de Francisco Durán. Sobre estos autores, véase F. AguiLar Piñal, Un escritor ilustrado: Cándido María Trigueros, CSIC, Madrid, 1987 y J. Cavipos, Teatro y sociedad en España (1780-1820), Moneda y Cambio, Madrid, 1969.

${ }^{28}$ Cf. R. DE la Cruz, Obras, Cano, Madrid, 1786, pp. liv y lv-lvi.

${ }^{29}$ Precisamente Moratín observó en el Discurso histórico sobre los orígenes 
de una forma bastante natural los escritores se escapan de las limitaciones que el concepto de imitación les imponía.

Para que este cambio de actitud se diera tuvo bastante importancia la literatura moral y la literatura parodística y burlesca, que era, según Jauss, una "forma invertida de imitatio" "30. Desde el punto de vista del lenguaje, tanto como desde el de las acciones y los argumentos, esta literatura se opone a la "culta", utilizando precisamente aquellos registros que ésta dejaba fuera. Como dice Michel Guillot, refiriéndose a Scarron, era "una revancha de la vida sobre la literatura". De todas formas, no podemos estar seguros de que esta literatura se proponga algo más que la imitación paródica de modelos literarios serios. Ahora bien, al presentarnos al personaje en un marco más cotidiano, e incluyendo el humor, este género de literatura contribuyó a variar el enfoque de los autores, abandonando los héroes trágicos y acercándolos a los "vulgares". Novelas como el Quijote y las picarescas (que quedaban fuera de las preceptivas), comedias como las burlescas, las moijigangas, los entremeses, etc., estaban contribuyendo al cambio que venimos estudiando.

Se vuelve sobre el presente. Se quiere explicar (o al menos reproducir) lo que sucede. Los autores empiezan a ser cronistas de la época. A este respecto, son importantes los periódicos, que dan cabida ya a asuntos propiamente cotidianos y costumbristas ${ }^{31}$. Más interés tiene, sin embargo, el acceso de la masa anónima al periodismo. Cualquiera que sepa escribir puede mandar cartas a los periódicos: puede exponer sus opiniones privadas y convertirlas en opiniones públicas. Nunca antes se había dado este hecho, que va a tener grandes consecuencias en la vida civil y en

del teatro español, $B A E$, t. 2, que R. de la Cruz logró "la imitación exacta [...] de las modernas costumbres del pueblo".

${ }^{30}$ Véase H. R. Jauss, Experiencia estética y hermenéutica literaria, Taurus, Madrid, 1986, p. 305.

${ }^{31} \mathrm{La}$ enorme cantidad de escritos me exime de citarlos. Valgan como ejemplos Beatriz Cienfuegos, La pensadora gaditana, Madrid, 1763; Ignacio DE LA ERBada, Los fantasmas de Madrid y Estafermos de la Corte, Madrid, 1761; Juan Antonio Mercadal, El duende especulativo sobre la vida civil, Madrid, 1771, con trabajos como "Galanteos y matrimonios a la moda", "Sobre los cafés" y otros. Interés tiene señalar cómo se intenta crear una opinión instrumentalizando este medio de comunicación desde el poder. Con el despotismo ilustrado se inician los mecanismos para legitimar desde la democracia el control de los pueblos y su manipulación, y el empleo de la prensa para crear opinión será decisivo, como supo ver en 1864 MAURICE JOLy, Diálogo en el infierno entre Maquiavelo y Montesquieu, Muchnik, Madrid, 1974. 
la forma de entender la realidad. La prensa tendrá un papel destacado en la consolidación del individualismo, al dar entrada a todos aquellos que quieran exponer sus opiniones, su crítica, sobre los más diversos asuntos. Y hablarán sobre aquello que les atañe, es decir, sobre el presente; y la realidad, también desde esta perspectiva, se convertirá en materia literaria ${ }^{32}$.

¿Qué es lo que desencadenó estos cambios? ¿Qué hizo que la realidad se viera con posibilidades para la ficción? Vamos a verlo desde los cuatro puntos a que antes me referí.

a) Es indudable que la filosofía sensista tiene gran importancia. Locke, Condillac, Newton, Bacon y otros científicos y representantes de la nueva filosofía fueron conocidos relativamente pronto en España, como demostraron ya Quiroz-Martínez, Froldi, Sebold y otros ${ }^{33}$. Cadalso había leído las obras de Newton y Locke. Meléndez conocía a Condillac y a Locke, igual que Jovellanos. Feijoo, antes que todos ellos, se muestra baconiano e introduce esta nueva filosofía y el racionalismo ${ }^{34}$.

La filosofía sensista se asume de muy diversas maneras. Una de las más interesantes es cómo la liberalización científica pasa también al ámbito estético. Es decir, de qué forma el descubrimiento de nuevas leyes pasa también a la literatura. Así, los preceptos de las poéticas se convierten en "leyes que no fueron inventadas, sino descubiertas", como dice Iriarte en Los literatos en

32 Tenemos un buen ejemplo en el discurso 163 de El Censor, titulado "Carácter de Eusebio, o reflexiones sobre la ociosidad". Allí se dice que un noble inculto insulta a un burgués llamándole "hombre nuevo". Éste responde: "Soy nuevo [...] es decir que vine al mundo antes que mi fortuna; que ésta es obra mía [...]; que mis acciones no son imitadas sino imitables; que soy original, no copia [...]. Soy nuevo; es verdad''. Otros ejemplos en esta línea podemos encontrar en los discursos 60 y 162 . Véase la edición de García Pandavenes, con prólogo de J. Fernández Montesinos, Labor, Barcelona, 1971.

33 Véase O. Quiroz-MarTínez, La introducción de la filosofía moderna en España, El Colegio de México, México, 1949; R. Froldi, "Apuntaciones críticas sobre la historiografía de la cultura y de la literatura españolas del siglo xVIII", NRFH, 33 (1984), 59-72; R. P. Sebold, "La filosofía de la Ilustración y el nacimiento del Romanticismo español", Trayectoria del Romanticismo español, Crítica, Barcelona, 1983; J. M. López Piñero, La introducción de la ciencia moderna en España, Ariel, Barcelona, 1964.

34 Véanse, por ejemplo, F. Aguilar Piñal, La biblioteca de Jovellanos, CSIC, Madrid, 1984 y G. STIFfoni, "La biblioteca de fray Martín Sarmiento. Apuntes para la historia de la penetración de las nuevas ideas en la España de Feijoo", 'Homenaje al profesor Carriazo, Universidad, Sevilla, 1973, t. 3, pp. $463-489$. 
Cuaresma ${ }^{35}$. Siendo esto así, y considerando que el hombre conoce el mundo gracias a sus sensaciones, puede permitirse cuestionar el pasado y cuanto ha heredado de él. Avalada por el pasado novator, se da un recrudecimiento de la "querella entre los antiguos y modernos", que teóricamente había dejado zanjada W. Grimm en 1756, en la Correspondence littéraire, cuando observó que no se debía confundir el progreso de las ciencias, siempre acumulativo, con los dominios del genio y del espíritu, donde cada autor es un universo aislado y como tal debe ser juzgado ${ }^{36}$.

Aunque Grimm separe los dos campos, lo cierto es que la actitud liberadora de los científicos influyó de forma decisiva en la de los literatos. Con bastante frecuencia encontramos unidos en los versos de los poetas dieciochescos los nombres de Milton, Virgilio, etc., a los de Newton, Condillac y otros científicos, como ya mostró Joaquín Arce ${ }^{37}$.

Desde luego es importante la filosofía sensista para que este cambio en el concepto de imitación se diera, pues contribuía a liberar el campo de expresión y de imitación, pero no insistiré en ello, pues la influencia del sensismo en la literatura ha sido ya bastante estudiada.

b) Pasaré ahora a tratar la presión que la corriente que he llamado "tradicionalista" ejerce durante todo el siglo, defendiendo su estética y su manera de entender lo literario. Para ejemplificar esta corriente me basaré sobre todo en el Discurso crítico que Erauso y Zabaleta publicó en 1750 . No sé si conocía las obras de Newton, Locke y otros, pero las ideas que expresa son muy semejantes. Y muy parecidas a las de españoles como Huarte de San Juan, Herrera o Zapata. Herrera, al anotar a Garcilaso en 1580, observaba que los antiguos "hombres fueron como nosotros, cuyos sentidos y juicios padecen engaño y flaqueza, y así pudieron errar y erraron". Erauso dirá: reconozcamos el saber de los antiguos, pero estemos seguros "de que fueron capaces de errar, y de que erraron mucho"38. Por su parte Zapata, en la Silva de cosas curiosas de 1592, reflexionaba así: "en las ciencias y artes hace el tiempo de agora al antiguo muchísima ventaja”.

${ }^{35}$ T. 3, Madrid, 1805 , p. 73.

${ }^{36}$ Cit. por MORTIER, op. cit., p. 52.

${ }^{37}$ La poesía ilustrada, Alhambra, Madrid, 1980.

38 T. Erauso y Zabaleta, Discurso crítico sobre el origen, calidad y estado presente de las comedias en España, Imprenta de Juan de Zúñiga, Madrid, 1750, p. 55. 
Haciéndose eco Erauso de las palabras de Feijoo 39, "nada tiene el hombre más inconstante que el gusto", escribe que el arte "pende siempre de la aprehensión e inconstancia del gusto, por lo regular antojadizo, melindroso y novelero. Esto supuesto, ¿qué reglas pueden subsistir invariables, si el objeto se funda sobre la base de la mutabilidad?" 40 Son palabras semejantes a las que Philoaletheias escribió, aunque dichas treinta y siete años antes. Es verdad que la intención de Erauso es defender la tradición castiza española, pero es también cierto que esa defensa traía consigo consecuencias liberadoras, pues propugnaba una noción de imitación mucho más amplia. Al igual que otros teóricos ingleses y franceses, reflexiona: si los antiguos escribieron según su época, hoy lo harían acomodándose "con los tiempos, con los usos, con los genios y con los gustos de ahora" 41 .

La imitación no debe tener limitaciones ni reglas, pues si las tiene "padece el fin [de la obra], se malquista el gusto, se aventura el útil, se engaña la curiosidad y se desfigura la imitación" 42 . Y más adelante señalará que a la naturaleza, rica, variada y dinámica, "no se la encarcela con prisiones [...] a fin de que no pueda imitar sino una parte mínima de aquel inmenso todo [ . . . ] haciendo supresiones, quiebros y trucamientos que no estaban en el original" 43 .

Erauso escribe este Discurso desde el punto de vista del espectador, considerando el efecto que el teatro produce en él. Por este motivo, la imitación debe llegar hasta el final: debe ofrecer lo que promete, ya que si el autor se muestra "restringido, diminuto en el poder y en el permiso", al público le parecerá "'mal desempeñado, pues no apura todo lo que concibe y promete dentro de una línea que se hizo objeto de atención" 44 .

El teatro es el ejercicio de la imitación de la Naturaleza, no de modelos de poesía dramática. Durante el siglo asistiremos a la independización del teatro respecto de la poesía dramática. Tendrá sus propias leyes y convenciones. Erauso, consciente de este carácter convencional de la escena, no piensa que con la imitación se persiga conseguir el efecto de "ilusión", pues "aun los

39 "Vicios y virtudes", Teatro crítico universal, Lorenzo Francisco Mojados, Madrid, 1726, t. 1, disc. 2, p. 39.

${ }^{40}$ Erauso, op. cit., s. p.

${ }^{41}$ Ibid., p. 56.

42 Ibid., p. 35.

${ }^{43}$ Ibid, , pp. 232-233.

${ }^{44}$ Ibid., p. 235. 
más lerdos y negados concurrentes a los Coliseos, saben, distinguen y conocen muy bien que cuanto ven sobre el tablado es fingimiento y no realidad, es pintado y no vivo, y es artificiosamente imitado y no existente" "45. Con esta observación entra en conflicto con los que pensaban que de la imitación se seguía la ilusión de lo imitado. Entiende el teatro como diversión ${ }^{46}$, y aquí choca con opiniones como la de Bernardo de Iriarte que, adelantándose a Stanislawski, observó: “'Todo representante debe figurarse que el lienzo o telón está echado o que media entre él y el espectador una pared de dos varas de grueso; y de aquí debe sacar que en su representación no tiene parte el público"47.

Estas opiniones se dirigen en dos sentidos contrarios. La de Erauso va hacia el público: arte como imitación de convenciones sociales asimiladas y esperadas por el espectador, con un gran margen de libertad en la imitación. La de Bernardo de Iriarte: arte como imitación de modelos ideales universales, en la que nada tiene que ver el público, al que no hay que considerar.

La polémica sobre si existía o no ilusión se desató en el último decenio del siglo, aunque de manera poco sonada. Por ejemplo, Arteaga pensaba que

la ilusión que producen las artes representativas no es ni puede ser completa, porque siempre queda el conocimiento expreso de que lo que se ve es una cosa imitada y no verdadera [ . . . ]. Y es tan cierto que la ilusión no es completa, que si por pocos minutos lo fuera, el espectador cambiaría de ideas y de afectos ${ }^{48}$.

Si Arteaga señalaba que la ilusión era el resultado de aceptar las convenciones -definición que Díez González dio después (1793): ilusión es “imitación según las reglas de cada arte" "49, Estala, ese mismo año iba más lejos, mostrándose contrario al concepto en el Discurso preliminar a su traducción de Edipo tirano: “Ningún espectador sensato puede padecer ilusión, ni por un momento, en el teatro; sabe que ha ido a ver una representación, no un hecho verdadero"'50.

${ }^{45}$ Id.

46 Ibid, p. 56.

${ }^{47}$ Cf. E. Cotarelo y Mori, Iriarte y su época, Madrid, 1897, p. 423. Véase también el Memorial literario de abril de 1784 , agosto de 1788 y junio de 1789 .

${ }^{48}$ E. DE ARTEAGA, La belleza ideal, ed. M. Batllori, Espasa-Calpe, Madrid, 1955 , p. 14.

${ }^{49}$ Díez González, op̀. cit., p. 75.

${ }^{50}$ P. DE Estala, "Discurso preliminar" a su traducción de Edipo tirano de Sófocles, Madrid, 1793. 
Las críticas teatrales nos dan ejemplos de cómo era esta ilusión. En El Censor, por citar sólo un ejemplo, leemos que se vio naufragar en una comedia a "un hombre y dos mujeres detrás de un lienzo que parecía barco y que daba fuertes columpiadas, tanto, que se les veía el cuerpo por debajo de la proa y de la popa".

Ahora bien, si se daban estos casos, en los que la ilusión no funcionaba, también ocurría lo contrario: casos en los que el público se veía absolutamente entregado, diríamos que identificado con lo que sucedía. Estala propone para esta posibilidad, en vez de ilusión, el término simpatía, que es una cierta identificación con los sucesos de la escena, precisamente porque se está fuera de ella. De esta forma explica la cantidad de lágrimas que vertían los espectadores y la moda de la sensibilidad, que era en cierto modo resultado del sensismo.

Pero la simpatía se producía también de otra forma. En la crítica de El maestro de Alejandro, de Fernando de Zárate, que apareció en el Correo de los ciegos del 16 de agosto de 1788, se cuenta que los actores ejecutaron la discusión entre Alejandro y Julia

con el mayor primor, acompañando los desdenes de Alejandro con un chistoso culeteo de sillas, viva pintura de los muchos pasajes semejantes a éste que pasan en el Avapiés y Barquillo [...]. A una moza que estaba en la cazuela y que hacía poco había presenciado un lance en todo idéntico a éste entre su Manolo y una chusca de las Maravillas, se le fueron las aguas de puro gozo $[\ldots]^{51}$.

La simpatía se da con aquello que representa lo cotidiano o tiene que ver con ello. Pero es necesario que se presente esa realidad de una forma especial: con cierta exageración o hipérbole que desemboque en lo cómico, como en el ejemplo, o en lo melodramático. Así se llega a producir esa huella en el espectador. Esto es lo que explicará en parte el éxito de las comedias y novelas sentimentales. La "estética del exceso", como la llamó Peter Brooks" Desde presupuestos tradicionalistas llegamos a esta forma de imitación que es un redescubrimiento de la realidad, de la "vida civil y costumbres españolas" de Ramón de la Cruz.

51 Véase más desarrollado este asunto en mi trabajo "Desarrollo del teatro popular a finales del siglo XVIII", Actas de las Jornadas sobre teatro popular en España, eds. J. Álvarez Barrientos y A. Cea Gutiérrez, CSIC, Madrid, 1987, pp. 215-225.

${ }^{52}$ P. Brooks, The melodramatic imagination, Columbia University Press, New York, 1985. 
Por un lado, el sensismo: como escribió Philoaletheias, "el gran punto es sentir y saber analizar los sentimientos" 53 . Por otro, la presión tradicional. Pasemos ahora a considerar la vertiente que busca la originalidad.

c) En el siglo XviII, ser original se entendía como el ejercicio de la crítica, pues era éste, además, uno de los mejores modos de mostrar la individualidad, dentro de esos márgenes apuntados antes, establecidos por el propio lema de la Revolución Francesa. Pero, ¿qué significaban originalidad y original en el siglo?

Eran sinónimos de algo o alguien "ridículo". Esta acepción permanece fuerte durante todo el siglo. Pero paralela a ella va la acepción positiva. El abate Feraud, en su Dictionnaire critique de la langue française (1787), dice que un "autor original es un hombre de genio". Feraud acoge la opción valorada estética y vitalmente por Diderot varios años antes en su Salon de 1767, en su novela El sobrino de Rameau y en multitud de cartas y artículos periodísticos. De manera semejante, para Alexander Gerard (1774), An essay on genius, "genio es propiamente la facultad de invención" 54 .

Sin embargo, si acudimos a la Enciclopedia, encontramos una definición ambigua, oscilante entre las dos acepciones: "es una manera de ejecutar una cosa común, de una forma singular y distinta: la originalidad es muy rara". Por este camino, intentando conciliar ambas posturas, Coleridge dirá en su Biographia literaria, "encontrar la no contradicción al unir lo viejo con lo nuevo [ . . . ] es el carácter y el privilegio del genio" 55 .

El sentido negativo de la palabra se fue neutralizando, según Mortier, a partir de 1762, de forma que en 1798 el Diccionario de la Academia francesa especifica ya "originalidad de carácter, de estilo, de pensamiento". La noción posterior de genio - en el sentido que los románticos dieron a la palabra- comienza aquí. Después se hablará de la sinceridad, inspiración y autenticidad del artista, pasando antes por la "autenticidad natural" de Rousseau ${ }^{56}$.

53 Philoaletheias, op. cit., p. 272.

${ }^{54}$ Cf. el libro de Mortier ya citado, cap. 2.

${ }^{55}$ Véase el interesante trabajo de LoY D. MARTIN, "Changing the past: theories of influence and originality, 1680-1830", Dispositio, 11/12 (1979), 189-212.

${ }^{56}$ Recordemos las palabras de J. VALERA sobre la "aparición del genio" en literatura. Refiriéndose a la novela naturalista, escribió en "Apuntes sobre el nuevo arte de escribir novelas", Obras completas, Imprenta Alemán, Madrid, t. 26, 1910: "Lo que sí había en el socialismo de los románticos, que se ha 
Uno de los hitos en ese camino hacia la liberación en la imitación fue la carta que E. Young dirigió a Richardson en 1759, publicada bajo el título Conjectures on original composition. Young piensa que "cuanto menos copiemos a los autores famosos de la antigüedad", más nos pareceremos a ellos.

Las distintas acepciones de original y autor que registra el Diccionario de Autoridades no aluden a cuanto hemos dicho hasta ahora. Imitar es "procurar ejercer las acciones o los ejemplos de alguno a semejanza suya, o hacer cualquier cosa a semejanza de otra", (s.v. ). Definición de 1734. Sin embargo, al definir inventar e invención sí se considera lo nuevo, pero no en relación con el arte. Inventar es "discurrir ingeniosamente algún artificio u otra cosa de nuevo". Invención es también "discurrir un engaño o mentira", es el artificio retórico ${ }^{57}$. Es en los tratados de arte donde primero he encontrado la acepción que nos interesa. Palomino en 1715, al tratar de lo "original", dice que es "lo inventado". Sempere y Guarinos nos explica el motivo de esta parquedad de opiniones en cuanto a lo original y por qué se tendía tan poco a la innovación en España. Considera que la causa es "la delicadeza suma con que los Españoles han mirado siempre los establecimientos de sus mayores y la nimia escrupulosidad con que han seguido sus pisadas y los usos establecidos". Esto "les hacía mirar toda innovación como peligrosa a la Religión y al Estado" 58.

Sólo Terreros, que yo sepa, alude a originalidad en este sentido entre los años 1786 y 1787 :

\footnotetext{
transmitido íntegro a los naturalistas, es un desprecio del vulgo, cuya felicidad se procuraba, y un absurdo endiosamiento de los hombres de letras. La palabra genio [...] se empezó a aplicar y a prodigar a los que escribían [...]. De la adoración de estos hombres se hizo una religión y casi un culto [ . . .]" (pp. 257-258). Y en otro lugar, refiriéndose a los años de 1840, dice: "Entonces estaba de moda y se hacía gala de no estudiar, porque los genios todo lo saben"; cf. A. Jiménez Fraud, Juan Valera y la generación de 1868, Taurus, Madrid, 1973, p. 87. Sobre la autenticidad como valor literario, nacida de Rousseau, que desemboca en la idea del genio, véase Mortier, op. cit., caps. 4 y 5. Para la alusión posterior a Young, el cap. 3 de esta obra.

${ }^{57}$ Fejoo habla de original en su discurso titulado "Mapa intelectual", pero se refiere a las ciencias, a la física.

${ }^{58} \mathrm{~J}$. Sempere tradujo libremente el tratado de Muratori sobre el buen gusto. Allí antepuso un "Discurso sobre el gusto actual de los españoles en literatura", Reflexiones sobre el buen gusto en las ciencias y las artes, Sancha, Madrid, 1782, p. 221. Véase también el artículo citado de MarTin.
} 
Autor original es el que ha sacado una obra o libro, el primero en aquella materia, o el que la aumenta, o la trata mejor que los demás.

Original llaman al Autor de una obra de invención o ingenio, y a la obra misma, al pensamiento nuevo, etcétera.

Su definición de invención también tiene interés:

el ingenio y perspicacia para hallar alguna cosa de nuevo, ya sea fuerza de discurrir, o ya de experimentar, o de uno y otro... [también] la misma cosa hallada o producida de nuevo, como parto propio, y sin auxilio o hurto de trabajo alguno ${ }^{59}$.

La relación que cuanto vengo diciendo tiene con el concepto de buen gusto es indudable. El buen gusto, más que cualquier otra noción teórica, es el que rige el ejercicio artístico en esos años. En Madrid tuvimos una Academia del Buen Gusto entre 1749 y 1751, estudiada por el profesor Caso, en la que convivieron armónicamente poetas de dispares gustos estéticos, unidos por la afición a la poesía. Su pluralidad de perspectivas e ideas llevó a la interrelación de influencias ${ }^{60}$.

Con una idea muy distinta a la que supone tendrían los poetas de esta Academia, habla Winckelmann del buen gusto. Observa en 1755 que el valor del artista se debe medir por la novedad de sus ideas, pero que éstas se deben mantener dentro del buen gusto ${ }^{61}$. Su reflexión nos sirve para dar a este concepto una dimensión más amplia que la meramente literaria o artística. El buen gusto es una categoría filosófico-moral relacionada con el tópico del sensus communis, con implicaciones sociológicas fuertes, pues en relación con ese ideal de buen gusto se formará una buena sociedad, distinguible por su uniformidad de intereses y homogeneidad de juicios. Esta buena sociedad, formada en algunos casos por elementos provenientes de clases bajas que ascienden por

${ }^{59}$ E. de Terreros y Pando, Diccionario castellano..., Viuda de Ibarra, Madrid, 1786-1788, s.v. Estas definiciones tienen bastante que ver con la que ConDILI.AC; da de original en su Essai sur l'origine des connaissances humaines (1773), para quien la invención "consiste en hacer nuevas combinaciones". Para esto es necesario tener talento o genio. Según Condillac, "el hombre genial tiene un carácter original, es inimitable" (I, II, \& 104). La traducción de éste, como de los otros pasaies, es mía.

${ }^{60}$ Cf. J. M. Caso González, " La Academia del Buen Gusto y la poesía de la época”, La época de Fernando VI, Cátedra Feijoo, Oviedo, 1981, pp. 383-418.

${ }^{61}$ Cit. por MorTier, ap. cit., p. 47. 
el poder económico y por miembros de la nobleza con actitudes burguesas, será caracterizable por su semejanza de comportamiento y su disparidad de procedencia. Tal disparidad va a suponer un mundo privado diferente (con sus distintos gustos privados silenciados frente al "buen gusto" público). Por este motivo, entre otros, se publicaron numerosos textos que tendían a conformar la imagen y el comportamiento de esa nueva figura que era el "buen ciudadano". Por citar sólo un ejemplo, véanse los Diálogos instructivos sobre las obligaciones del buen ciudadano a la Patria (Madrid, 1770).

Este buen gusto debía ser, por tanto, moral y artístico, sentimental y racional, pero sobre todo público, pues era un signo de identificación social y de asimilación a una clase dominante ${ }^{62}$.

Pero el buen gusto tenía también una vertiente utilitarista, instrumental, como correspondía al movimiento de la llustración. Habrá que educar al pueblo. El buen gusto no se medía por los sabios aislados que hubiera en una nación, sino por lo extendida que estuviera la cultura entre la población. "Hasta que la educación disponga generalmente a los jóvenes a pensar bien, y a formar exactas ideas de las cosas, no se debe esperar que el Buen Gusto arraigue y sea común en ningún pueblo", dirá Sempere ${ }^{63}$.

En aras del decoro, del buen gusto, de la verosimilitud de la imitación, se vio necesario que los actores vistieran y se comportaran según la época, la clase, la nación a la que perteneciera el personaje que incorporaban. Al pedir este ajuste en la indumentaria se pone de relieve la consideración de que los hombres son distintos. Son históricos y, por tanto, las referencias locales, temporales, climatológicas, se vuelven necesarias ya que no sólo van a determinar al personaje, sino que lo van a hacer más verosímil, más real en definitiva. El personaje será lo que haga y diga en

62 Véase T. Egido López, Opinión pública y oposición al poder en la España del siglo XIIII (1713-1759), Universidad, Valladolid, 1971; N. GLendinNing, "Cambios en el concepto de opinión pública a fines del siglo xVIII", $N R F H$, 33 (1984), 157-164; J. Habermas, 'Historia crítica de la opinión pública, Gustavo Gili, Barcelona, 1986; R. Sennetr, El declive del hombre público, Península, Barcelona, 1978.

${ }^{63}$ Op. cit., p. 221 . En las pp. 23-24 observa que el buen gusto es la reunión ajustada de la filosofía y la erudición. Tocaría ahora discutir hasta qué punto se estaba por la labor de "ilustrar" a la población. Numerosos son los testimonios que hablan de "adecuar" la instrucción del pueblo en función de su trabajo, condición social, etc. Las "luces" debían descender gradualmente según de quién se tratase. 
un tiempo y un momento. Sabemos que antes de esta época no se daba especial importancia a este aspecto de la representación. Lo intemporal de la indumentaria ponía de relieve lo convencional del hecho teatral. Como escribió Auerbach, los hombres, antes del xvill, pensaban que Homero era su contemporáneo ${ }^{64}$. El hecho mismo de sentir el teatro clásico español como antiguo abona esta interpretación. Como dije antes, interesa el hombre presente y en su historia, porque los modos de relación han cambiado, como han cambiado las formas de expresión y el lenguaje poético. Incluso la consideración del clima como un determinante, no ya sólo de las costumbres vitales, sino también de las estéticas, indica lo mismo ${ }^{65}$.

d) Todos estos cambios van a traer consigo la aparición de nuevos géneros literarios, poniendo de manifiesto que los antiguos no podían reproducir las características del momento. El más destacado fue la comedia sentimental, llamada por Diderot "género serio", y así llamada también por Juan Andrés. Observemos que esta denominación prepara al melodrama.

El abate Juan Andrés, en su Origen, 'progresos y estado actual de toda literatura, observa que la tragedia urbana "sabe muy bien herir el corazón con apasionados afectos, e inspirar una útil moralidad, y [...] tal vez logra más cumplidamente el fin deseado del teatro de deleitar e instruir'"66.

Dejando a un lado la traducción de Luzán de la pieza de Nivelle de la Chaussée y los ejemplos de Trigueros, Jovellanos, Valladares, Comella o Zavala, las palabras de Diderot en sus Conversaciones sobre "El hijo natural", de 1757, y las de Beaumarchais en La madre culpable, nos explican cómo ha cambiado la sensibilidad y el nuevo carácter de lo imitado. Igual que Juan Andrés después, Diderot observa que este "género serio" está más próximo a nosotros:

Es el retablo de las desgracias que nos rodean. ¿Acaso no podéis imaginar el efecto que os produciría una situación real, vestidos de hoy, diálogos ajustados a las acciones, acciones naturales, peligros que habéis temido para vuestros padres y amigos, y para vos mismo? Un revés económico, el miedo a la vergüenza, las consecuen-

${ }^{64}$ Véase E. Auerbach, Mimesis, FGE, México, 1959

65 Puede encontrarse ejemplos en Muratori, Diderot, Vico, García de la Huerta y antes en Saavedra Fajardo, "Empresa 81"

${ }^{66}$ JuAn ANDRÉs, Origen, progresos y estado actual de toda literatura, Sancha, Madrid, 1787, t. 4. 
cias de la miseria, una pasión que conduce al hombre a su ruina, de su ruina a la desesperación, de la desesperación a la muerte violenta, no son sucesos raros, ¿y no creéis que os afectarían tanto como la muerte fabulosa de un tirano, o el sacrificio de un niño en el altar de los dioses de Atenas o Roma? ${ }^{\text {67 }}$

Diderot expresa así la gran revolución estética y social que se está dando. Interesan los problemas del momento y la comedia sentimental se hace eco de ellos (igual que la comedia ilustrada), presenta al hombre en sociedad, en familia, afirmando sus valores, como ha dicho Beaumarchais. Años después, Díez González escribirá: "las acciones urbanas (las que presenta esta comedia). . . son las que comúnmente pasan entre personas de un carácter regular'.

Con este género serio se hacía más viable la educación del público, pues se hacía tomando ejemplos de la vida real, de forma que la semejanza entre su mundo y lo que veía en escena era enorme. Pero, ¿quiénes eran esas "personas de un carácter regular" a las que se refería Díez González? Diderot nos dio respuesta a esta pregunta en sus Conversaciones, al decirnos quiénes debían figurar en el escenario: "el literato, el filósofo, el comerciante, el juez, el abogado, el político, el ciudadano, el magistrado, el financiero, el intendente, [...] el padre de familia, el esposo, la hermana, los hermanos"'68.

Diderot y todos los que escribían comedias sentimentales e ilustradas se servían de estos personajes para reproducir la realidad y al mismo tiempo para fijar los valores morales del nuevo grupo social emergente, que era además el principal destinatario de tales espectáculos.

Este nuevo grupo dará origen a la burguesía decimonónica. Si podemos decir que existió una incipiente burguesía, formada por elementos de dispar procedencia, quizá sea más acertado pen-

${ }^{67}$ D. Diderot, Oeuvres esthétiques, ed. P. Vernière, Garnier, Paris, 1959, pp. 136 y 149. La traducción es mía. BEAUMARCHAIs, en Le matiage: la mère coupable, dice que el "drama" reflejará la nueva clase, íntima, sensible e instruida..., "pinta a grandes trazos al hombre viviendo en sociedad, su estado, sus faltas y sus desdichas, con la verdad evidente que la exageración misma, que hace brillar los otros géneros, no permite siempre tener tan fielmente" (Nota preliminar). Cit. por J. A. MARAVALl, "Del despotismo ilustrado a una ideología de las clases medias: significación de Moratín", CILFM, pp. 177-178.

${ }^{68}$ Op. cit., p. 154. Y añade Dorval: “ ¡El padre de familia! ¡Qué tema, en un siglo como el nuestro, donde parece que no se tiene la menor idea de lo que es un padre de familia!" 
sar que en los últimos decenios del siglo xvIII lo que existe más propiamente son actitudes que después se llamarán burguesas. Si pensamos que en el xvill expañol existían ya grupos burgueses, no debemos darles una imagen semejante a la que la burguesía tiene en el siglo xix. Actitudes de aquellos grupos pasarán a la burguesía decimonónica: el valor de la familia como institución social y económica, las relaciones con el poder, la consideración del dinero como un valor determinante y organizador de la estructura vital, criterios capitalistas o precapitalistas, etc. En un principio la burguesía se muestra como un grupo movilizador, permeable, en el que se proyecta la idea del individuo como triunfador. Con el tiempo esa idea desaparecerá, y será cuando la burguesía esté ya consolidada como clase y dificulte el acceso a quienes quieran pertenecer a ella.

La familia, por tanto, será fundamental para dar cohesión a la nueva sociedad. La institución familiar se convertirá en interés económico y social; es decir, será la familia, no la persona individual, la que acumule riquezas, y será ella la que las posea más allá de las personas individuales, puesto que éstas mueren. Los negocios familiares, y los intereses que esos negocios generen, serán los que dicten las normas de conducta, los valores, la moral. Y el teatro, como la novela, contribuirá a esta consolidación.

Por eso resulta interesante constatar, también, de qué manera coincide la explosión de ediciones de libros sobre los deberes de la familia, del buen padre para con sus hijos, etc. - tendentes a consolidar las relaciones de la familia-, con el entendimiento de ésta como un valor económico. El negocio, la economía, se basa en el intercambio, en el largo plazo; las inversiones dan sus beneficios en el futuro. Por otra parte, los negociantes se fían de las firmas de las familias que han demostrado solidez económica y seriedad negociante en el pasado. Fijémonos en que hasta hace relativamente poco, las firmas no indicaban el ramo al que se dedicaban. Bastaba con el nombre: "J. Fernández e hijos", "Sucesores de J. Fernández", etc. Se sabía, por tradición familiar, a qué negocios se dedicaban esas firmas ${ }^{69}$.

La familia integra la sociedad, y son las familias las que demuestran el éxito del sistema que llamaremos burgués. La novela contemporánea, la comedia sentimental y la comedia ilustrada pre-

69 Véase, aunque referido al siglo XIX, el precioso artículo de A. Flores, “Los gritos de Madrid o la publicidad en 1850", en La sociedad de 1850, ed. J. Campos, Alianza, Madrid, 1968, pp. 22-31. 
sentarán generalmente al hombre en familia. Veremos conflictos familiares, interiores de casas decentes y honestas, familias arruinadas por el vicio paterno, exaltaciones del trabajo y de los "buenos modales", etc. Cuando Romà y Rossell hable de la industria como motor de la sociedad y del matrimonio se estará refiriendo a esto. La familia es el grupo que defiende la propiedad privada, es decir, el núcleo social. Por esto era muy importante para la sociedad naciente contar con expresiones artísticas que la identificaran. No sólo el teatro o la novela tendrán esta función. La pintura, la música, la escultura contribuirán también.

Pero hay más. Con la aparición y consolidación de la burguesía, es decir, del triunfo del individualismo, se potencia la escritura de biografías. Biografías que no son ya sólo (como antes) de artistas. Son biografías de militares, diplomáticos, creadores de imperios económicos, políticos, en definitiva, de hombres públicos, que ponen de relieve el éxito de una clase pero también el valor del esfuerzo personal. La burguesía mediatiza y consolida así sus valores, su ser, con todos sus defectos y virtudes. Se erige en proyecto de vida, en aspiración, en salvadora, gracias a la galería de éxitos, retratos individuales que aspiraron a llegar a la burguesía y lo lograron. Kracauer ha hablado de "la biografía como forma de arte de la nueva burguesía"70; pongamos ahora nosotros en relación este culto al individualismo burgués (que no es tal, pues sólo ofrece una posibilidad) con el culto al "genio", individual. Valera lo criticó, pero llegó más lejos al señalar que la pertenencia a la burguesía limitaba el conocimiento de la realidad, la expresión literaria y la de sus observaciones, puesto que debía ajustarse a las "buenas formas" sociales ${ }^{71}$.

Están ocurriendo varias cosas. Por un lado, esa "buena sociedad" se está consolidando económicamente y está adquiriendo el poder que antes tenían los aristócratas, porque tiene los medios de producción y distribución de la riqueza. Como consecuencia literaria se plantearán en el teatro y en la novela problemas

70 S. Kracauer, La massa come omamento, Prismi, Napoli, 1982, pp. 143-147.

71 VALERA, en "De la naturaleza y carácter de la novela"' (1860), Obras completas, t. 2, pp. 296-297, señala: "En el modo en que vivimos, particularmente los individuos de la clase media, tenemos [...] que ajustarnos a cierta pauta, todo lo cual mengua y descabala y aun destruye la autonomía novelesca [...]'. Continúa señalando la importancia del dinero en la burguesía y en el arte. Cf. también, para una historia de los buenos modales, S. GIneR, "El rapto de la moral: mudanza de la virtud cívica en la sociedad corporativa', $R O_{c c}, 45$ (1985), 47-68. 
que aludan a estos aspectos, y en la poesía de tinte conflictivo como la de Arroyal y algunos fabulistas. Diderot lo señaló antes, refiriéndose a los "reveses económicos". Añadamos ahora que los aristócratas suelen aparecer en estas obras como los malos, como los que forjan la injusticia y se aprovechan de las jóvenes de clase inferior, que son ejemplos de moralidad (lo mismo pasaba en las novelas). Los "nuevos burgueses" no podían identificarse con las formas artísticas anteriores; ni la comedia ni la tragedia los retrataban; sin embargo, este nuevo género serio se basaba en ellos y los presentaba de una forma agradable. Ellos son el ejemplo, pero también, naturalmente, ellos son los destinatarios y los que compran las obras. Comienza aquí el proceso por el cual la burguesía se apropia del arte, de la cultura, y los utiliza en beneficio propio. Al mismo tiempo, con esta visión maniquea del bien y del mal - malos los que no sienten, no lloran y son aristócratas; buenos, los que lloran y pertenecen a la clase media - se inicia el camino hacia el melodrama, máxima expresión de la sensibilidad burguesa y de los cambios en el concepto de imitación, entendido éste como redescubrimiento de la realidad. Desde este punto de vista, vemos también la incidencia del sentimentalismo en el cambio del gusto estético.

Bousoño, en Teoría de la expresión poética, piensa que este maniqueísmo se debe al tópico de la "justicia poética"72. Creo, sin embargo, que hay más implicaciones. El hombre ilustrado del XVIII cree en la sociedad, en las instituciones y en su funcionalidad, y quiere sobre todo que el pueblo también crea en ellas. Por eso la educación popular, por eso también la literatura sobre instituciones y las obras relativas a la justicia, a los delitos y a aquellos que representan a la ley. Es cierto también, por otra parte, que castigar al malo y premiar al bueno es un motivo muy productivo en la literatura y que siempre se ha utilizado, en cierto modo, para contrarrestar el efecto de la realidad, que suele actuar del modo contrario. Cuando se pierda la fe en las instituciones, en la sociedad, la literatura reflejará este hecho, y "la sociedad" será la culpable de las desdichas de los hombres. Estaremos ya en el Romanticismo.

Pero aún seguimos en el siglo xviIr. Ahora bien, la imitación, lo que se imita, ha cambiado. Se hace literatura sobre el presente, se "siente" el presente. Diderot, con sus declaraciones, puso de manifiesto el cambio que se ha dado en la dirección de la imi-

72 T. 2, Gredos, Madrid, 1970, p. 128. 
tación. Si antes iba de la obra al universo o al ideal de Naturaleza que se tenía, ahora va de la obra al público. La imitación se convierte en un instrumento para producir sensaciones en el público. Y, por eso, el autor debía colocar ante el público a aquellos que eran sus iguales, pues así la impresión se lograba más fácilmente. Oscar Wilde tenía razón, por tanto, cuando decía que "es el espectador y no la vida lo que el arte realmente refleja",73.

El foco de muchos autores que escribieron a finales del siglo XVIII cambió radicalmente de dirección. Sin embargo, no todos se dedicaron a escribir sobre el presente con los nuevos géneros; fueron muchos los que, utilizando fórmulas antiguas como la tragedia, filtraron motivaciones y problemas del momento, como señaló Glendinning recientemente en un trabajo sobre la tendencia liberal a finales del Xvin ${ }^{74}$. De estar limitados a la imitación más o menos amplia de modelos literarios o de la Naturaleza idealizada, pasaron a reproducir lo que observaban, lo que sentían ellos y creían que sentían o podrían sentir sus lectores ${ }^{75}$. La literatura, en cierto modo, se vuelve íntima: de los campos y de los caminos pasa a la ciudad. Y, dentro de la ciudad, se introduce en las casas para describirnos la vida familiar y privada.

Como he dicho ya, lo que interesa es el público, el efecto; por eso lo que se ve hay que ajustarlo a unas normas comprensibles para ese público y con las que se pueda identificar. Serán las del buen gusto. Porque, más que antes, el público está haciendo uso del arte, está poniendo más en la contemplación de la obra artística porque se está contemplando.

A finales de siglo la imitación sufre cambios porque refleja los cambios sociales. Por esto es importante lo económico para entender la naturaleza del objeto literario en esa época y la transformación de los géneros, porque lo económico está matizando todos los aspectos de la sociedad, y llega también al mundo literario y al mercado editorial. Los traductores traducen lo que se vende. Los dramaturgos ofrecen al público lo que a éste le gusta, pues es el que paga. Los novelistas, y tenemos las declaraciones de Tójar y Valladares, por ejemplo, escriben sus novelas para satisfa-

73 Cit. por M. Abrams, El espejo y la lámpara, Barral, Barcelona, 1975, p. 59.

${ }^{74} \mathrm{~N}$. Gi.endinning, "Tendencias liberales a fines del siglo xviri en la literatura española", Dieciocho, 9 (1986), 157-164 [Homenaje a I. L. McClelland].

${ }^{75} \mathrm{Y}$ a este respecto, nuevamente DIDEROT tiene palabras acertadas: "Lo que es preciso que el artista halle es lo que todo el mundo diría en semejante caso, lo que nadie oiría sin reconocerlo inmediatamente en sí mismo", op. cit., p. 168. 
cer la demanda de este género de literatura. La evolución literaria se comienza a vincular a la económica, política y social.

En este nuevo mundo, la "imitación" se ve más como un plagio que como una cualidad necesaria a los autores. Al entrar en contacto la obra de arte con el mundo económico se ponen en juego factores que antes no se consideraban. El poeta del Renacimiento, que escribía para sus amigos, imitaba los modelos valorados. El autor del xviII comienza a vivir de su literatura, se ve inmerso en el sistema de la oferta y la demanda, considera al receptor y sus gustos, aunque se rebele muchas veces contra ellos; el caso es que no puede seguir imitando modelos que tal vez están valorados por la tradición, pero que no tienen vigencia y no son aceptados, o son desconocidos, por ese público que, ahora más que antes, debe pagar por tener una experiencia o una sensación estética. Cuando el arte se hace público, y lector y espectador comienzan a interferir en la consideración de los géneros, modelándolos, el autor no puede ser ajeno a esta presión. La imitación de modelos antiguos quedará reducida, entonces, al peoueño gruoo de conocedores de la Historia de la Literatura, seguramente sin incidencia sobre el gusto de la masa lectora, mientras que la realidad seguirá ofreciendo materia literaria a cuantos escritores se acerquen a ella.

Joaquín Álvarez Barrientos Instituto de Filología, CSIC 